This is the peer reviewed version of the following article: ChemCatChem 2016, 8, 21 - 33, which has been published in final form at http://dx.doi.org/10.1002/cctc.201501269. This article may be used for non-commercial purposes in accordance with Wiley Terms and Conditions for Self-Archiving.

\title{
Advances in the Design of Nanostructured Catalysts for Selective Hydrogenation
}

Gianvito Vilé, ${ }^{[a]}$ Davide Albani, ${ }^{[a]}$ Neyvis Almora-Barrios, ${ }^{[b]}$ Núria López, ${ }^{[b]}$ and Javier PérezRamírez ${ }^{*[a]}$

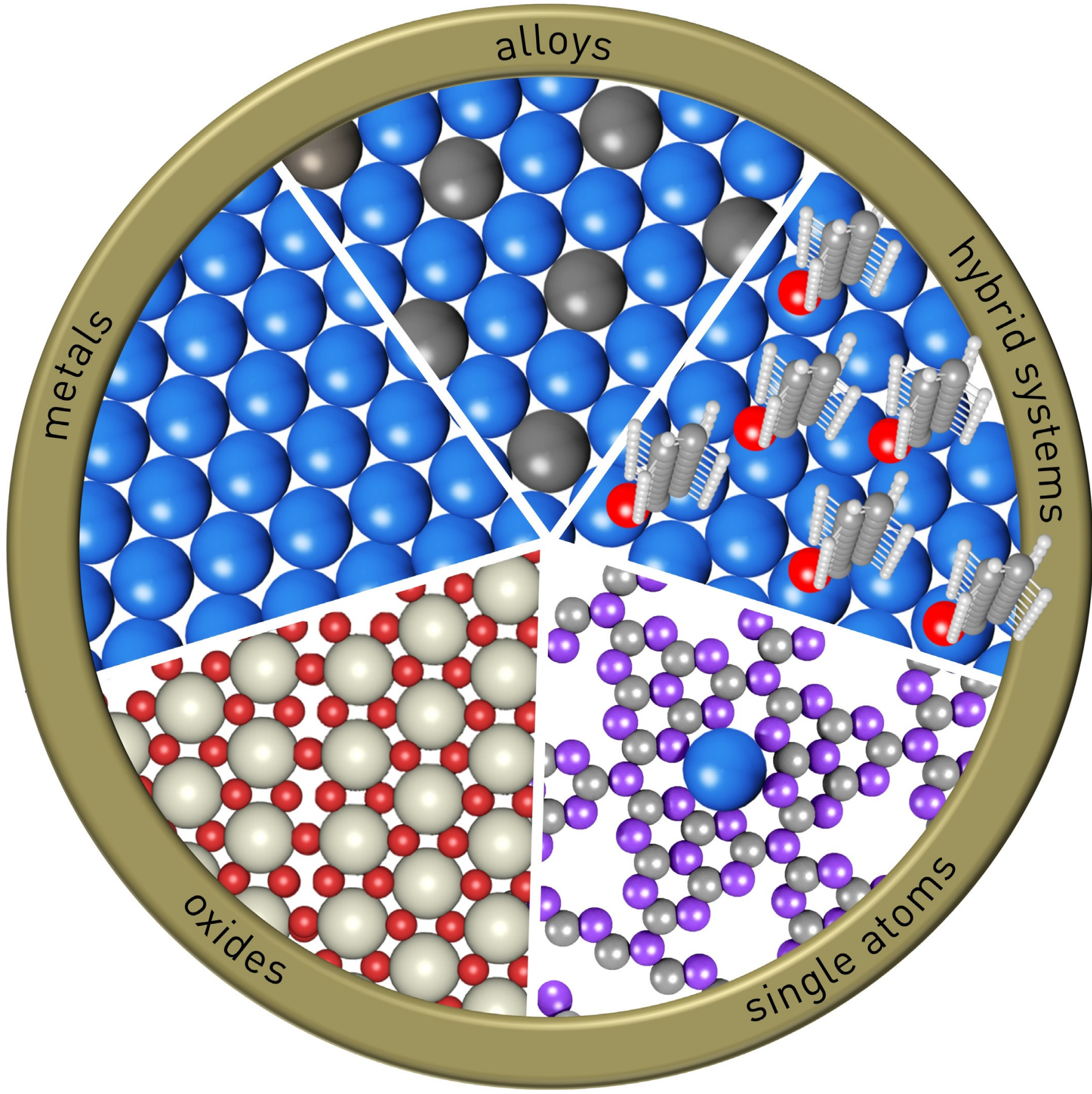


Selective hydrogenations lay at the heart of many industrial processes. The archetypal catalysts for this class of reactions are generally prepared by 'metal poisoning' strategies: the active metal is protected and selectively deactivated with various compounds. This approach has been applied for decades, with limited understanding. Low product selectivity and presence of toxic elements in the catalyst pose severe constraints in the utilization of these materials in the future. Thus, to develop more sustainable catalysts, this field has recently gained momentum. This Review analyzes the concepts and frontiers that have been developed in the last decade: from nanostruc- turing less conventional metals in order to improve their ability to activate $\mathrm{H}_{2}$, to the use of oxides as active phases, from alloying, to the ensemble control in hybrid materials, and site isolation approaches in single-site heterogeneous catalysts. Particular attention is given to the hydrogenation of alkynes and nitroarenes, two reactions at the core of the chemical industry, importantly applied in the manufacture of polymers, pharmaceuticals, nutraceuticals, and agrochemicals. The strategies here identified can be transposed to other relevant hydrogenations and can guide in the design of more advanced materials.

\section{Introduction}

Hydrogenations are among the pillars of the chemical industry. ${ }^{[1-4]}$ It has been estimated that approximately $25 \%$ of all chemical processes include at least a catalytic hydrogenation step. ${ }^{[5,6]}$ This, by some extent, contributes to ca. $8 \%$ of the world's GDP. Being the most applied reaction for the manufacture of chemicals, it is unsurprising that hydrogenations remain one of the widest areas of research in catalysis.

The pioneering works of Sabatier, ${ }^{[7]}$ Haber, $^{[8]}$ Horiuti, $_{1}^{[9]}$ Polanyi ${ }^{[9]}$ and Lindlar ${ }^{[10,11]}$ settled the grounds for many hydrogenation reactions; the concepts derived from their observations were successfully implemented in industrial practice. However, after the research of Lindlar, this field has been languishing for decades, with only minor contributions, and increasing compartmentalization between reactions conducted for bulk and fine chemical applications (Figure 1). The fine chemical sector, in particular, has relied for decades on the use of harmful heterogeneous catalysts and inefficient (batch) processes. This has also been ascribed to the fact that organic chemists with little skills in catalysis have dominated this type of practice. ${ }^{[12]}$

To address new safety and environmental challenges, ${ }^{[13]}$ the last decade has witnessed a revolution in the field. New catalytic materials have been developed and many more are awaiting further exploration. This has driven a mature 'sleeping beauty' into one of the most vivid, challenging, and fast-growing research fields in catalysis, able to provide, as in the early days, a wide, rich set of new, conceptual research directions.

By revisiting these concepts, this contribution highlights common denominators between the strategies that have been applied in catalyst design and the frontiers ahead. Considering the variety of hydrogenation reactions (Figure 2) and the fact

[a] Dr. G. Vilé, D. Albani, Prof. J. Pérez-Ramírez

Institute for Chemical and Bioengineering

Department of Chemistry and Applied Biosciences

ETH Zurich

Vladimir-Prelog-Weg 1, 8093 Zurich (Switzerland)

E-mail:jpr@chem.ethz.ch

[b] Dr. N. Almora-Barrios, Prof. N. López

Institute of Chemical Research of Catalonia (ICIQ) and Barcelona Institute of Science and Technology

Av. Països Catalans 16, 43007 Tarragona (Spain)

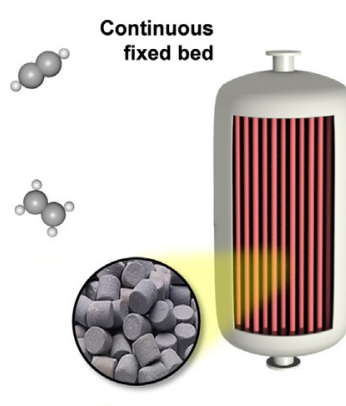

Bulk chemicals Simple chemicals . High volume $\left(>10^{9}\right.$ ton year $\left.{ }^{-1}\right)$. Low price $\left(<\$ 1 \mathrm{~kg}^{-1}\right)$.

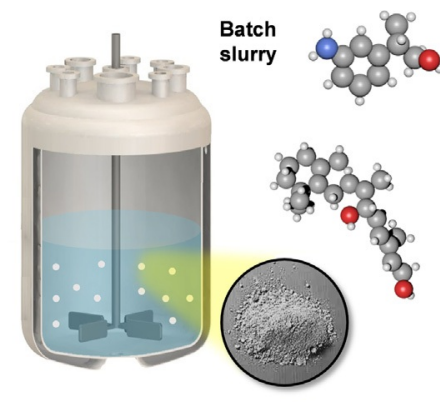

Fine chemicals

- High-added value chemicals - Low volume $\left(<10^{7}\right.$ ton year $\left.{ }^{-1}\right)$ - High price $\left(>\$ 10 \mathrm{~kg}^{-1}\right)$
Figure 1. The illustration depicts the strict differences in operation and market between hydrogenation reactions applied in the manufacture of bulk (left) and fine (right) chemicals.

that more than 15000 publications and patents have appeared in the last 10 years, it would be impossible to give a comprehensive description of the properties and applications of all the materials reported. Accordingly, this review targets the hydrogenation of alkynes and nitroarenes as two case studies. These reactions are industrially relevant, as they are involved in the synthesis of polymers (such as polyethylene, polypropylene, polyurethanes, and rubber additives), pharmaceuticals, vitamins, nutraceuticals, fragrances, and agrochemicals, and have been particularly studied in this decade, as more than 4000 contributions can be found in the literature.

\section{Poisoning as Design Strategy for Selective Hydrogenation}

From a mechanistic point of view, the hydrogenation of alkynes proceeds through the dissociative chemisorption of $\mathrm{H}_{2}$ and sequential addition of the dissociated $\mathrm{H}$ atoms to the acetylenic substrate, yielding the alkene (partial or semi-hydrogenation) and the alkane (over-hydrogenation)..$^{[, 14-17]}$ Similarly, the hydrogenation of nitroarenes involves hydrogen splitting, and reduction of the nitro group, nitroso intermediate, and hydroxylamine (Figure 3). ${ }^{[8,12,18]}$ In both cases, oligomers, isomers, 
and condensation products can be expected. Thus, a selective catalyst preferentially adsorbs and hydrogenates the reactive moiety, avoiding the consecutive hydrogenation of the product and of additional functional groups. ${ }^{[19]}$

Palladium and platinum are the preferred metal of choice for the hydrogenation of alkyne and nitroarene, respectively. ${ }^{[16,20,21]}$ Stopping the reaction at the product stage might be challenging, especially over these metals that are highly active in $\mathrm{H}_{2}$ splitting. ${ }^{[17]}$ For this reason, a kinetic selectivity factor is identified, defined as the ratio between the rate of selective hydrogenation and the rate of over-hydrogenation. ${ }^{[15,19]}$ In addition, a thermodynamic selectivity factor can be defined as the favorable adsorption of the reactant and the lack of adsorption of the product. ${ }^{[19,20]}$

Bare palladium and platinum have intrinsic low thermodynamic and kinetic selectivities (Figure 4). In fact, at moderateto-high hydrogen partial pressures, these metals incorporate $\mathrm{H}$ species in the lattice, forming hydrides. ${ }^{[19-23]}$ This will catalyze undesired reactions such as isomerization and hydrogenation of other functional groups. Similarly, in H-poor regimes, the adsorbed reactant may not find available $\mathrm{H}$ species in close proximity. Thus, coking and condensation reactions between adsorbed species could be favored. ${ }^{[23]}$ The presence of carbon fragments may induce the formation of $\mathrm{Pd}$ or $\mathrm{Pt}$ carbide phases, leading to a major drop in activity with a slight im-

\footnotetext{
Javier Pérez-Ramírez studied Chemical Engineering at the University of Alicante, Spain, and earned his Ph.D. at TU Delft, The Netherlands, in 2002. Since 2010, he has been a full professor of Catalysis Engineering at the Institute for Chemical and Bioengineering of ETH Zurich. He is engaged in the discovery and understanding of heterogeneous catalysts and reactor engineering concepts devoted to sustainable technologies. Current topics of interest include hierarchically organized materials, alkane functionalization, selective hydrogenations, and valorization of renewables.

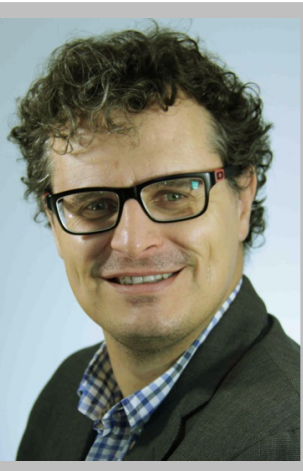

Núria López studied Chemistry at the University of Barcelona, Spain, and obtained her Ph.D. in 1999 from the same university. Her post-doctoral studies were carried out in the group of Prof. Jens K. Nørskov at the Technical University of Denmark. In 2005, she joined the Institute of Chemical Research of Catalonia (ICIQ) as a group leader. Her field of expertise is the use of computational simulations to model the structure and reactivity of heterogeneous catalysts.

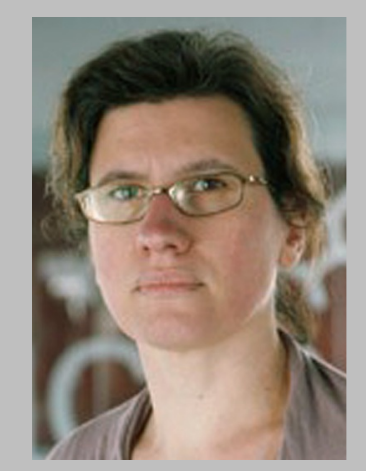

provement in selectivity. ${ }^{[21]}$ Hence, modifiers are required during both gas and liquid-phase operation. These modifiers tailor the size and energy landscape of the ensemble of atoms where the reaction occurs, suppressing the formation of hydrides and carbides and securing a high product yield (Figure 4). ${ }^{[23,24]}$ This approach is often referred to as 'selective poisoning' and is the conventional method applied in the design of heterogeneous catalysts for selective hydrogenations. For example, for gas-phase alkyne hydrogenation, the industrial catalyst is based on palladium (0.01-0.05 wt\%) promoted with $\mathrm{Ag}, \mathrm{Au}$, or $\mathrm{Cu}^{[2,16,17]}$ To further enhance the selectivity, CO can be fed with the reactants as a process modifier. ${ }^{[14]}$ For liquid-phase alkyne hydrogenation, the catalyst in practice is based on $\mathrm{Pd}(5 \mathrm{wt} \%)$ modified with $\mathrm{Pb}$ or $\mathrm{Bi}(4 \mathrm{wt} \%) .{ }^{[10,11]}$ In some cases, quinoline is added as a selectivity enhancer but then the total $\mathrm{Pb}$ loading is lower (Figure 5). ${ }^{[24]}$ For nitroarene

\section{Gianvito Vilé studied Chemical Engi-} neering at the Polytechnic University of Milan, Italy. After short stays at TU Delft, The Netherlands, and ETH Zurich, Switzerland, he conducted his Ph.D. studies at ETH Zurich. His research interests embrace the design of catalytic materials for selectivity control in organic reactions, as well as the application of flow chemistry, structured reactors, and novel reaction media for process intensification.

Davide Albani studied Industrial Chemistry at the University of Milan, Italy. Since 2014, he is a Ph.D. student at ETH Zurich, under the supervision of Prof. Javier Pérez-Ramírez. He researches the synthesis and catalytic properties of hybrid nanocatalysts in hydrogenations.

Neyvis Almora-Barrios studied Chemistry at the University of Havana, Cuba, and earned her Ph.D. in 2010, working in the group of Prof. Nora de Leeuw at the University College of London, UK. Since 2011, she is a Research Fellow at the Institute of Chemical Research of Catalonia (ICIQ) and, in 2014, she was the recipient of the Ayuda formación Posdoctoral fellowship from the Spanish Ministerio de Economia y Competitividad. She applies modelling tech-
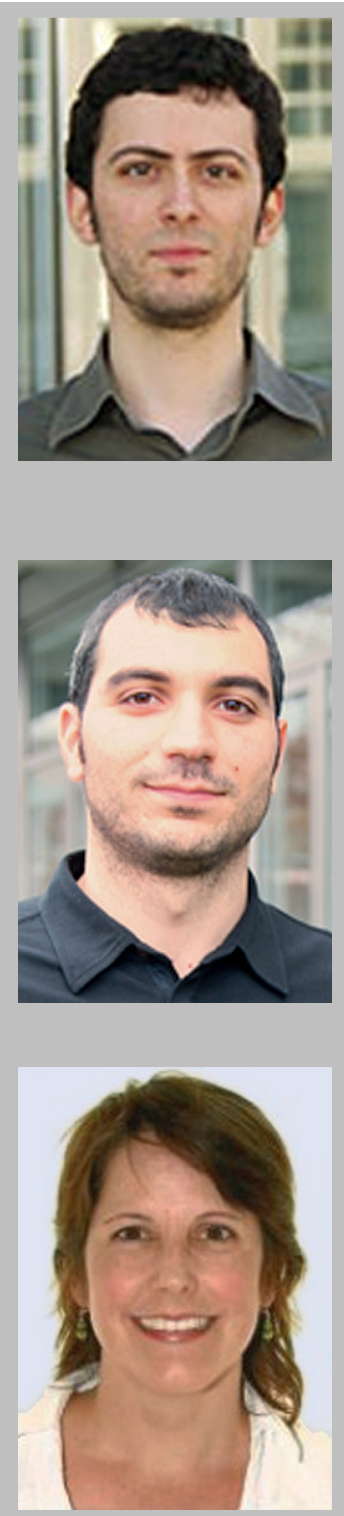
niques to study structure-properties relationships in heterogeneous catalysis. 


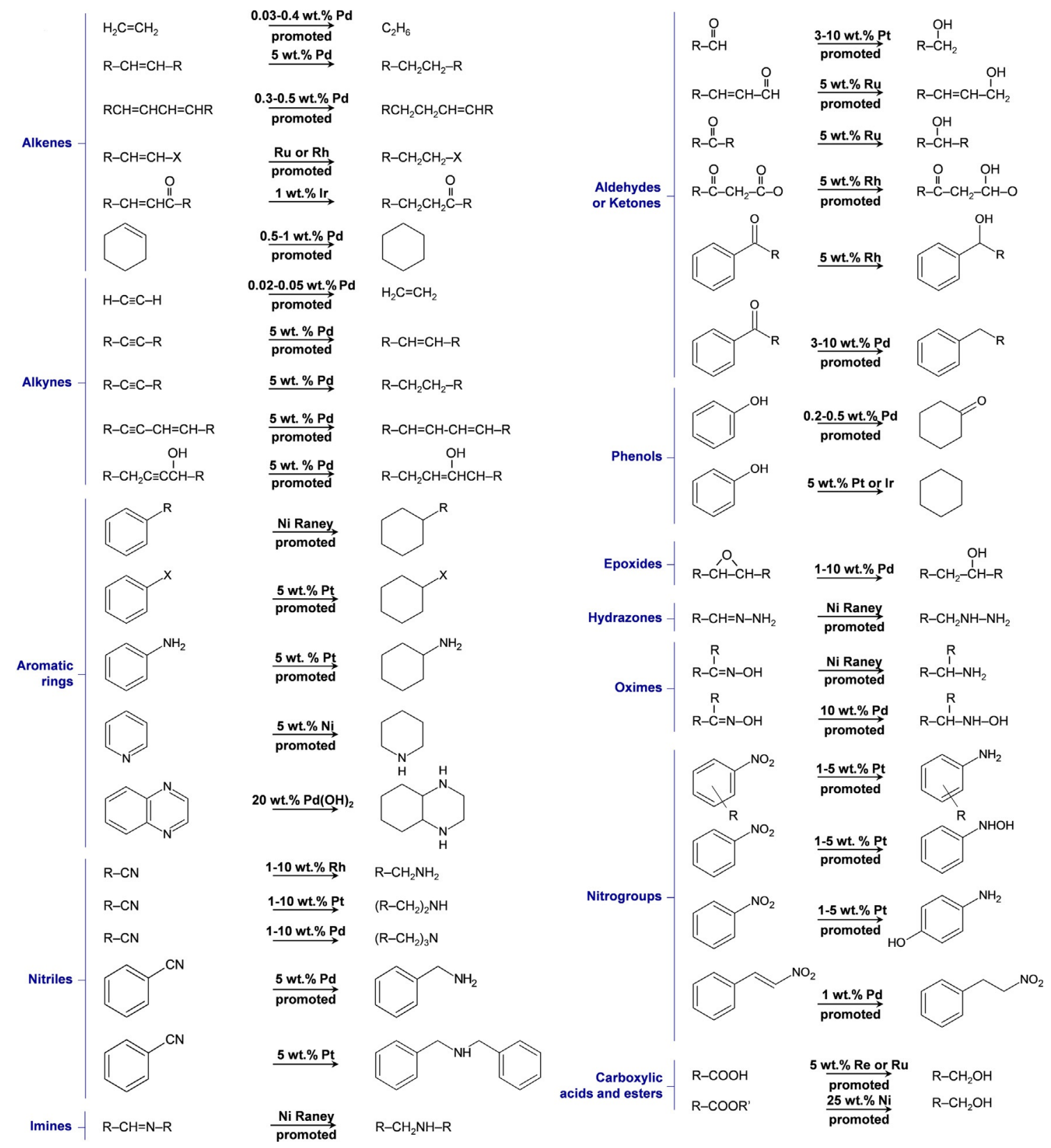

Figure 2. Overview of the typical active phases applied in hydrogenation reactions. The figure, which is adapted from refs. [1 and 2], highlights that the catalysts used for more than six decades in the chemical industry often contain an excessive amount of metals and promoters.

hydrogenation, Pt nanoparticles (5 wt \%) are modified with $\mathrm{Pb}$, $\mathrm{V}$, or other S, P, N, and Cl-containing species (1 wt \%). ${ }^{[12,25,26]}$

The improved activity and/or selectivity of these modified materials has been explained in terms of: 1) electronic effects, owing to the perturbation of the metal environment by the promoter, leading to changes in the mechanism of $\mathrm{H}_{2}$ activation, semi and over-hydrogenation; ${ }^{[19,20]}$ 2) geometric effects, owing to the reduction of the ensemble size, and confinement leading to a decreased number of adjacent adsorption sites, blocking diffusion paths of the organic fragments and limiting oligomerization and condensation reactions. ${ }^{[19,20]}$ The presence of modifiers to protect the active phase leads, on the other hand, to a low metal utilization. For instance, for the Lindlar catalyst applied in liquid-phase alkyne hydrogenation, it has been estimated that only $0.02 \mathrm{wt} \%$ of the total loading of precious metal (5 wt \%) is active during catalysis. ${ }^{[24]}$ This suboptimal atom efficiency and the presence of (often toxic) additives to poison the metal encourage the search for more sustainable and efficient hydrogenation catalysts. ${ }^{[27-29]}$

\section{Advances in Catalyst Design}

\subsection{Promoting Poorly Active and Poorly Selective Metals}

Less conventional metals, such as $\mathrm{Au}_{1}{ }^{[19,30]} \mathrm{Ag}_{1}{ }^{[31,32]} \mathrm{Cu}_{1}{ }^{[33]} \mathrm{Ni}_{1}{ }^{[34]}$ and $\mathrm{Fe}^{[35]}$ can be used to catalyze selective hydrogenations. 
(a)

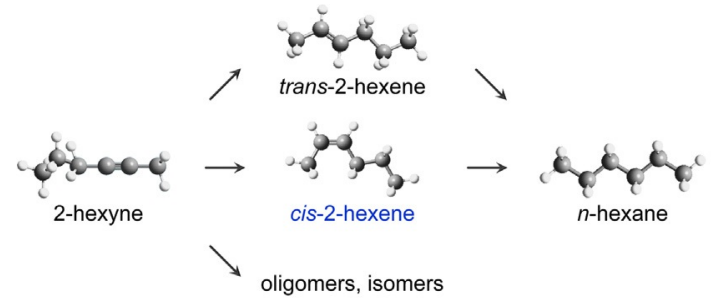

(b)

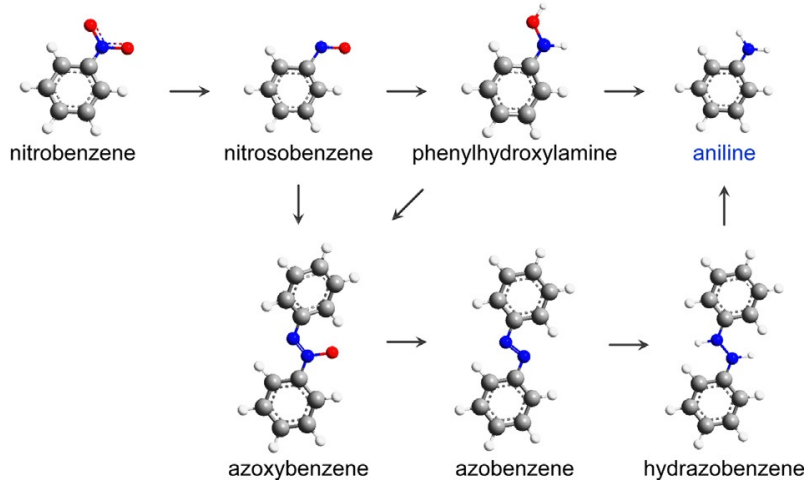

Figure 3. Simplified reaction network for the hydrogenation of (a) 2-hexyne and (b) nitrobenzene. The desired products are highlighted in blue.

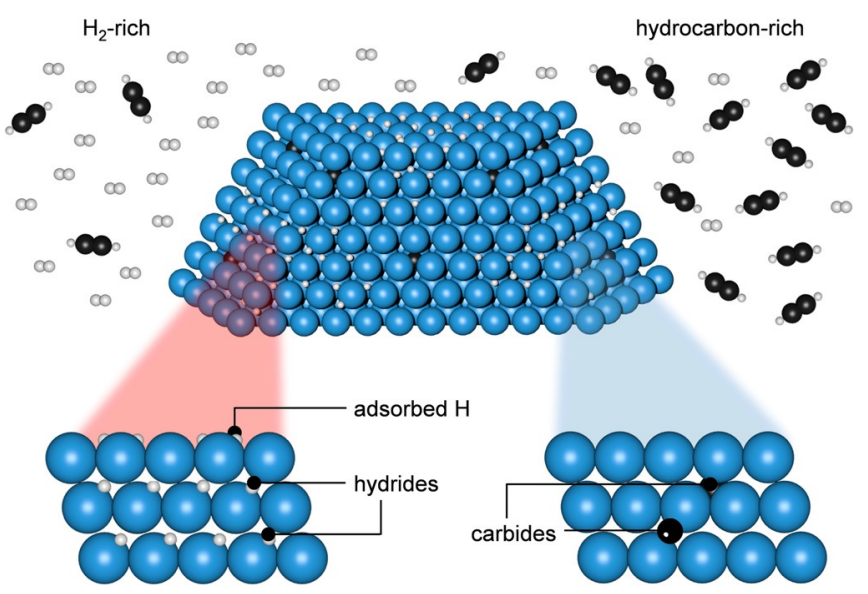

Figure 4. Bare nanoparticles of highly active metals, such as palladium and platinum, cannot catalyze hydrogenation reactions in a selective manner, because of the tendency to readily form unselective phases, such as hydrides (left) and carbides (right).

Some of these metals $(\mathrm{Au}, \mathrm{Ag})$ do not readily activate hydrogen. Their intrinsic low activity can be enhanced by nanostructuring the metal phase (Figure $6 a$ ), increasing the concentration of surface defects (e.g., steps, edges, and kinks) where the reaction occurs. In this context, Nikolaev and co-workers ${ }^{[36]}$ have prepared alumina-supported Au nanocatalysts with variable particle size $(2-8 \mathrm{~nm})$. Applied in acetylene hydrogenation, the materials showed a higher turnover frequency (TOF) and ethylene selectivity over smaller particles (Figure $6 \mathrm{~b}$ ). This result is opposite to what is expected over Pd-based catalysts, ${ }^{[37-42]}$ and could be attributed to the increased surface concentration of active corners and edges. ${ }^{[30]}$ Similarly, PérezRamírez and co-workers demonstrated that Ag nanoparticles with variable average particle size $(2-20 \mathrm{~nm})$ are highly selec-

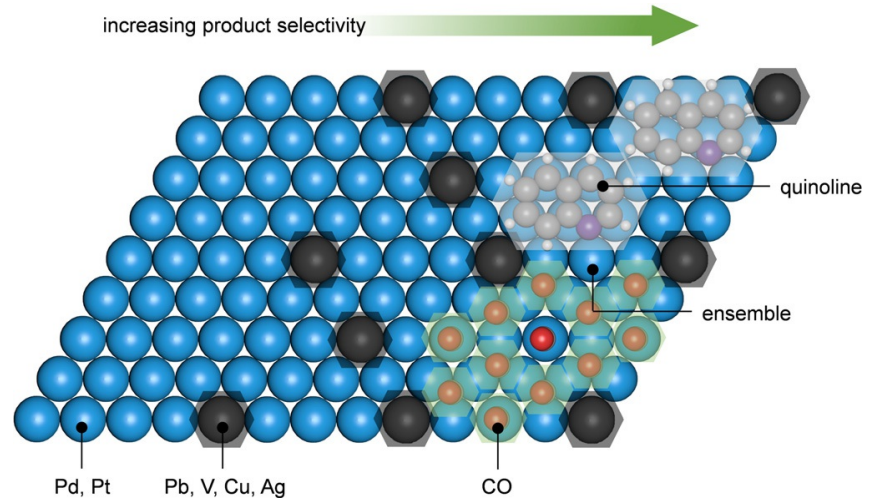

Figure 5. To improve product selectivity, highly active metals are generally protected with other elements and organic or inorganic compounds. This catalyst design strategy, which has been applied for decades in academia and industry, is often referred to as poisoning. The figure also highlights that the fraction of surface metal available for catalysis (ensemble) is reduced upon increased concentration of modifiers. (a)

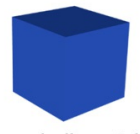

bulk meta

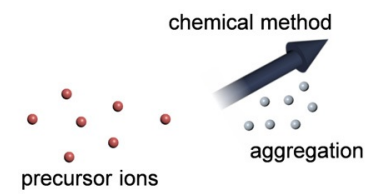

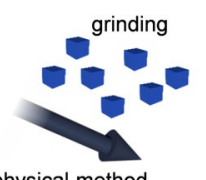

physical method
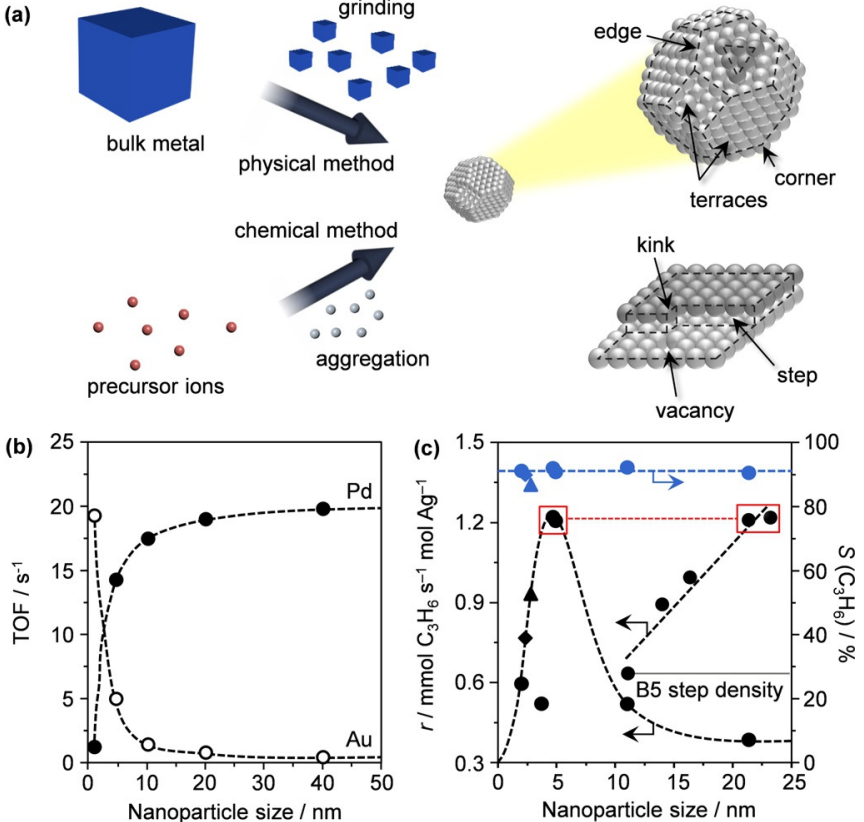

Figure 6. (a) Selection of research contributions, highlighting the possibility to tune the activity of less-conventional hydrogenation metals by introduction of surface defects. These defects can be created by reduction of the average particle size of the metal, using physical and chemical methods. Influence of the (b) Au and Pd, and (c) Ag particle size on the hydrogenation of acetylene and propyne. The figures are adapted from refs. [103] (a), [36] (b), and [31] (c).

tive in the hydrogenation of propyne. ${ }^{[31]}$ The maximal activity at approximately $4.5 \mathrm{~nm} \mathrm{Ag}$ particles (Figure $6 \mathrm{c}$ ) could be attributed to the presence of B5 sites, which combine (110) and (100) facets and are active centers in the reaction. Corma et al. ${ }^{[41]}$ also observed a significant increase in selectivity in the hydrogenation of 3-nitrostyrene and chloronitrobenzene (up to $99.6 \%$ at $96 \%$ conversion) with small crystallites of $\mathrm{TiO}_{2}$-supported $\mathrm{Au}(<5 \mathrm{~nm})$. This result was also attributed to the presence of low-coordinated sites where the adsorption of the re- 
actants is favored. $\mathrm{Cu}_{1}^{[33]} \mathrm{Ni}_{1}^{[34]}$ and $\mathrm{Fe}_{1}^{[35]}$ on the other hand, are quite active in hydrogen splitting, but poorly selective. The catalytic performance can be improved by alloying strategies. Among the excellent examples in the literature, Studt et al. ${ }^{[43]}$ performed a theoretical screening on a broad space of alloys and, aided by scaling relationships, discovered new selective acetylene hydrogenation catalysts ( $\mathrm{Ni}-\mathrm{Zn}, \mathrm{Ni}-\mathrm{Ga}$; Figure $7 \mathrm{a}-\mathrm{e}$ ). Bridier and Pérez-Ramírez made use of the unselective character of $\mathrm{Ni}$ and $\mathrm{Cu}$ surfaces, engineering a Cu-Ni-Fe catalysts that showed full selectivity in propyne hydrogenation (Figure $7 \mathrm{c}$ ). ${ }^{[4]}$ In situ X-ray absorption spectroscopy experiments demonstrated that $\mathrm{Ni}$ enhanced the surface $\mathrm{H}$ coverage and the reducibility of $\mathrm{Fe}$ and $\mathrm{Cu}$, producing a well-distributed $\mathrm{Cu}$ surface and hindering the catalyst re-oxidation that would favor Fe segregation. ${ }^{[45]}$ Armbrüster et al. ${ }^{[46]}$ prepared a stable Al-Fe catalyst for acetylene hydrogenation that showed high alkene selectivity (82\%) (Figure $7 \mathrm{~d}$ ). Using a bifunctional $\mathrm{Au}-\mathrm{Fe}_{2} \mathrm{O}_{3}$ catalyst, Corma achieved up to $99 \%$ selectivity for the hydrogenation of nitrostyrene. ${ }^{[4]]}$

\subsection{Oxides and Carbon Materials}

Oxides are traditionally considered not suitable hydrogenation catalyst owing to the presence of oxygen species that can be released in contact with $\mathrm{H}_{2}{ }^{[48]}$ The first reported hydrogenation reaction over a metal oxide dates back to 1948 , when Komarewsky and Coley discovered that vanadia-alumina catalysts could reduce alkenes, dienes, and acetylene, with $98 \%$ yields at $600 \mathrm{~K}^{[49]}$ Later, Ponec et al. reported the activity of selected metal oxides $\left(\mathrm{ZrO}_{2}, \mathrm{ZnO}\right.$, and $\left.\mathrm{CeO}_{2}\right)$ for the hydrogenation of benzoic acid to benzaldehyde. ${ }^{[50,51]}$ For two decades these works were completely ignored until, very recently the field has been revitalized. In a series of papers, Pérez-Ramírez and co-workers demonstrated that ceria is an ultra-selective catalyst for the gas-phase hydrogenation of acetylene and propyne ${ }^{[52]}$ and for the liquid-phase hydrogenation of more complex alkynes ${ }^{[53]}$ (selectivity to alkene of $90-100 \%$ at a rate of $10^{-3} \mathrm{~mol}_{\text {product }}$ mol $\left._{\mathrm{CeO}_{2}}{ }^{-1} \mathrm{~h}^{-1}\right)$. The absence of oxygen vacancies was found to be beneficial for attaining high performances. In addition, a large hydrogen excess in the feed mixture $\left(\mathrm{H}_{2} /\right.$ alkyne $>25$ ) and temperatures above $500 \mathrm{~K}$ were required. By tuning the crystal morphology of the ceria nanocatalysts, the authors also determined structure-performance relationships of ceria in acetylene hydrogenations. ${ }^{[54]}$ In fact, differently from oxidation catalysis (Figure 8), the (111) surface, prevalent in conventional $\mathrm{CeO}_{2}$ particles, appears to be more beneficial for the reaction in comparison with to the (100) surface. The groundbreaking nature of these investigations has opened up a bright, new field in catalysis, in order to understand the mechanism of hydrogenation of a metal oxide and the influence of doping strategies.

Density functional theory (DFT) calculations indicated that the oxygen atoms were active centers in the adsorption of all intermediates and reaction (Figure $8 \mathrm{a}$ ). Ceria, in fact, has the ability to activate hydrogen $\left(E_{\text {act }}>1 \mathrm{eV}\right.$ ) and stabilize acetylenic radicals, accommodating one electron into Ce $4 f$ level. ${ }^{[5]}$ The intrinsic anisotropy that drives site isolation of the active $\mathrm{O}$ and Ce centers inhibits oligomerization pathways and is key for the outstanding selective behavior of this metal oxide. López and collaborators ${ }^{[56,57]}$ proposed that the mechanism of
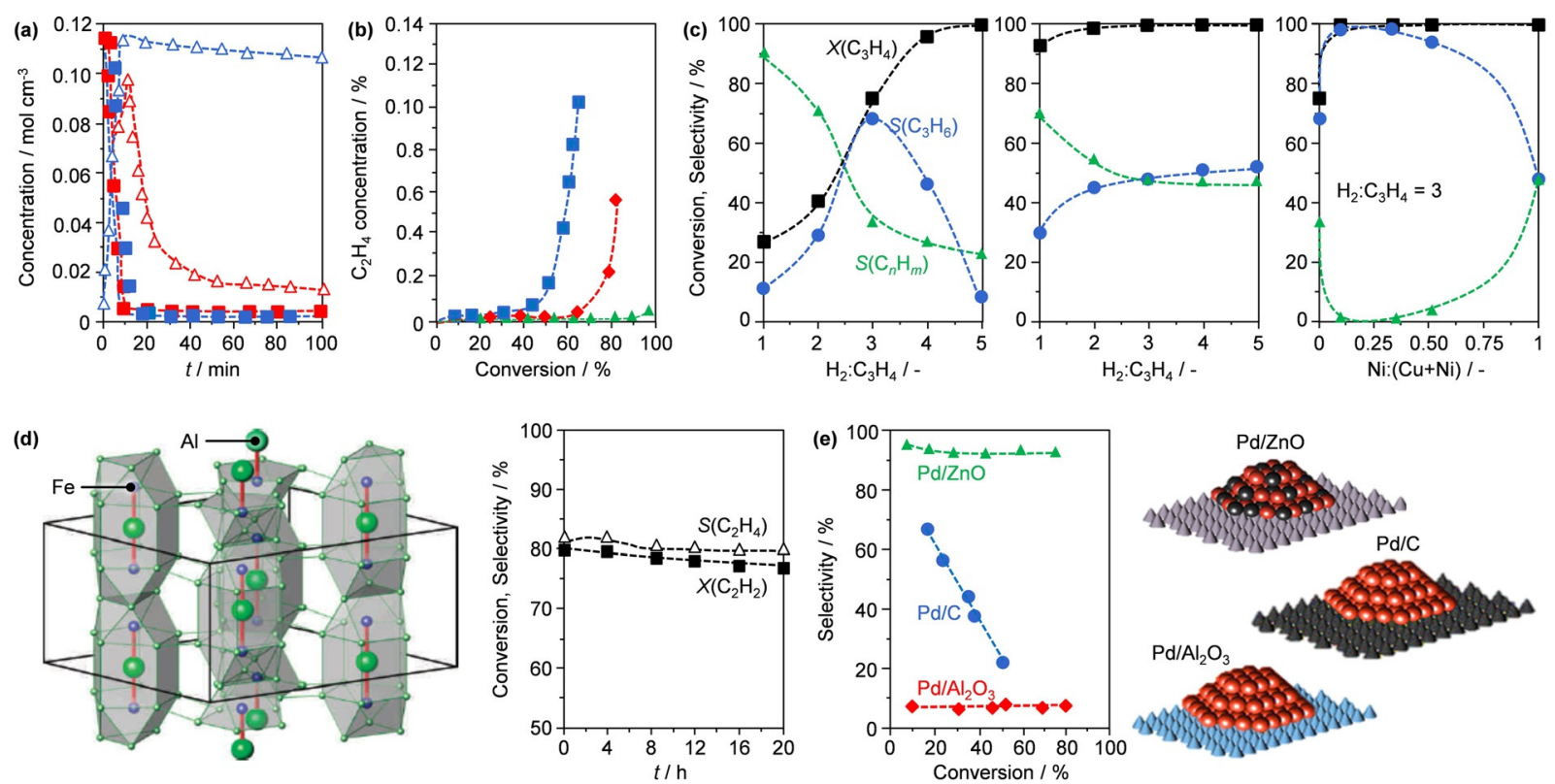

Figure 7. Selection of research contributions, highlighting the possibility to enhance the selectivity of typical hydrogenation metals by alloying. (a) Hydrogenation of 3-hexyne over Pd (red) and Pd-Bi (blue) at $373 \mathrm{~K}$; the concentration of 3-hexyne and cis-3-hexene are indicated with closed and open symbols, respectively. (b) Conversion of acetylene in the presence of $\mathrm{H}_{2}$ over Ni (blue), Pd (red), and Ni-Zn (green) model (111) surfaces. (c) Alkyne conversion and alkene selectivity in the hydrogenation of propyne as a function of the hydrogen-to-hydrocarbon ratio, over $\mathrm{Ni}$ (left), $\mathrm{Cu}$ (middle), and Fe-Ni-Cu (right) alloys at $523 \mathrm{~K}$. (d) Unit cell of $\mathrm{Al}_{13} \mathrm{Fe}_{4}$ and acetylene hydrogenation performance of the same catalyst at $473 \mathrm{~K}$ and $\mathrm{H}_{2}: \mathrm{C}_{2} \mathrm{H}_{2}=5$. (e) Selectivity as a function of the conversion in the hydrogenation of nitrobenzene over different Pd catalysts, at $500 \mathrm{~K}$ and 10 bar. The figures are adapted from refs. [79] (a), [43] (b), [44] (c), [46] (d), [94] and [95] (e). 


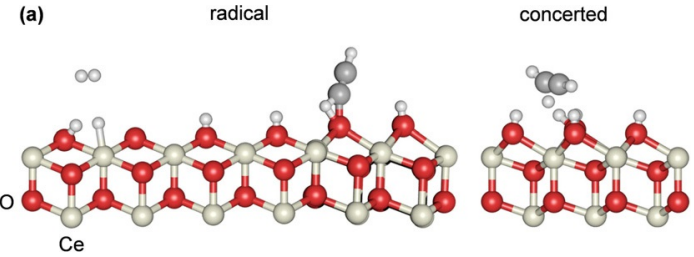

(b) nanocubes (NC)

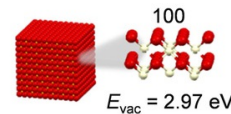

nanoctahedra (NO)
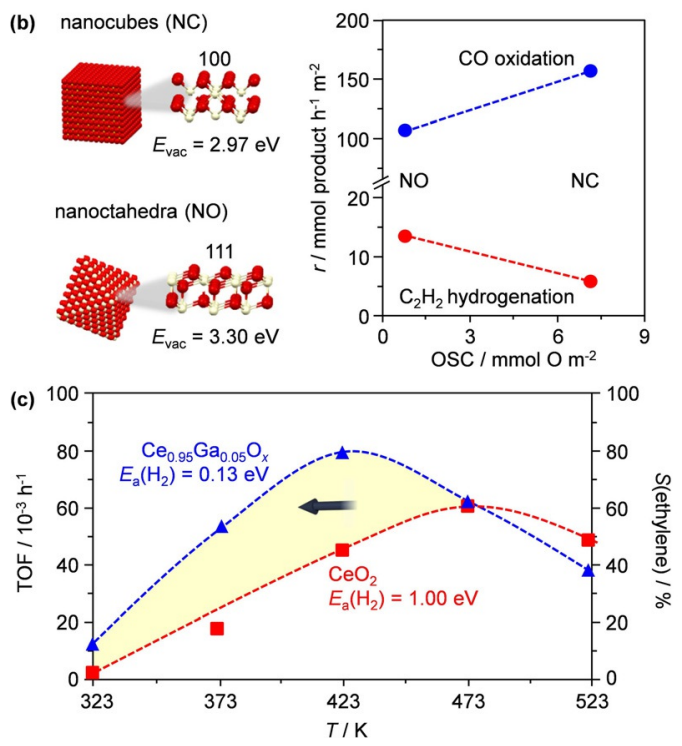

Figure 8. (a) Snapshot of selected steps involved in the mechanism of acetylene hydrogenation over $\mathrm{CeO}_{2}$. The steps highlight that the oxygen atoms (in red) are active sites. (b) Nanocube and nanoctahedra $\mathrm{CeO}_{2}$ morphologies with the preferentially-exposed facet and energy of oxygen vacancy formation. Reaction rate of the same materials in acetylene and $\mathrm{CO}$ oxidation. (c) Turnover frequency and selectivity to ethene in acetylene hydrogenation over $\mathrm{CeO}_{2}$ and $\mathrm{Ce}_{0.95} \mathrm{Ga}_{0.05} \mathrm{O}_{x}$. Adapted from refs. [52], [54], [55], and [57].

$\mathrm{H}_{2}$ activation involves a heterolytic pathway owing to the polarization and redox capacity of the cerium-oxygen bond. The presence of acid-base properties in ceria facilitating the splitting of hydrogen has been recently confirmed with spectroscopic techniques. ${ }^{[58]}$ After heterolytic splitting of the $\mathrm{H}-\mathrm{H}$ bond, the $\mathrm{H}$ atom on the cerium is transferred to the oxygen atom, reducing a Ce center and yielding the two hydroxyl groups. A similar activation path was later reported by Fernández-Torre et al. ${ }^{[59]}$ and Fabris et al. ${ }^{[60]}$

Unfortunately, compared to metallic catalysts, pure oxides lead to low reaction rates, and require high temperatures and $\mathrm{H}_{2}$ partial pressures. By tuning the reducibility of ceria, PérezRamírez and co-workers were able to demonstrate that trivalent cations, such as gallium and indium, enhance the reducibility of ceria and promotes the semi-hydrogenation of acetylene and propyne (Figure $8 \mathrm{c}){ }^{[61]}$ This enables a reduction of the operating temperature from 523 to $423 \mathrm{~K}$, while maintaining an outstanding ethylene and propylene selectivity (80$97 \%$ ), even in the presence of excess alkene in the feed. This ability of doped ceria to better activate hydrogen was corroborated with infrared spectroscopy, DFT calculations, and isotopic exchange experiments. ${ }^{[62-64]}$ Several open questions on to the proposed hydrogenation paths (i.e., the interplay between the radical $^{[55]}$ and concerted paths, ${ }^{[57]}$ the possible path of the oli- gomerization at high temperature) remain to be addressed and will require advanced characterization experiments. ${ }^{[64]}$

Following the results of ceria in alkyne hydrogenation, $\mathrm{Yu}$ and co-workers have recently demonstrated that ceria nanorods can efficiently catalyze the hydrogenation of nitroaromatics to amines (selectivity of $100 \%$ ) at $300 \mathrm{~K}$ and 1 bar. ${ }^{[65]}$ The intrinsic inability of ceria to activate hydrogen was circumvented by using $\mathrm{N}_{2} \mathrm{H}_{2}$ as reducing agent. Song et al. have discovered that tungsten oxide, another earth-abundant metal oxide with redox properties, catalyzes the selective hydrogenation of olefins and aryl-nitro compounds. ${ }^{[6]}$ Also in this case, the higher hydrogenation activity was found over the catalyst possessing the minimal concentration of oxygen vacancies. Metiu and coworkers have reported theoretical and experimental evidences that $\mathrm{La}_{2} \mathrm{O}_{3}$ is also able to split hydrogen with a mechanism that nicely parallel that by López. ${ }^{[67]}$ Thus, $\mathrm{La}_{2} \mathrm{O}_{3}$ might become another promising oxidic catalyst for new types of hydrogenations. Primo et al. ${ }^{[68]}$ finally showed that pure graphene can replace metals for hydrogenation of acetylene in the presence of a large excess of ethylene, with high selectivity and activity (selectivity to alkene of $98-100 \%$ at a TOF of $10^{2} \mathrm{~h}^{-1}$ ). DFT calculations are still required to rationalize the selective hydrogenation behavior of this carbon-based material.

The use of less conventional metals and metal oxides for the hydrogenation of more functionalized substrates is limited, owing to the required high temperatures and pressures for catalysis. ${ }^{[69-71]}$ At this condition, the high-added-value product generally decomposes. For example, oxenin, the acetylenic intermediate involved in the synthesis of vitamin A, thermally decomposes at approximately $350 \mathrm{~K}^{[69]}$ Thus, oxides are not suitable heterogeneous catalysts and alternative approaches should be investigated.

\subsection{Palladium and Platinum Alloys}

The selectivity provided by palladium and platinum catalysts can be enhanced by alloying strategies. This approach is particularly beneficial when mild reaction conditions are desired. Besides, the secondary or ternary metals provide ensemble control and electronic contributions on the adsorption of reactants and products. Many multimetallic materials have been developed and excellent reviews are available on the design and performance of active and selective hydrogenation catalysts. ${ }^{[72-74]}$ For alkyne hydrogenation, the majority of works has focused on modified Pd, since this active phase enables operation at temperatures below $300 \mathrm{~K}$; the catalysts developed were $\mathrm{Pd}-\mathrm{Ag}^{[75,76]} \mathrm{Pd}-\mathrm{Au}^{\left[{ }^{[77]}\right.} \mathrm{Pd}-\mathrm{Bi}^{\left[{ }^{[78-80]}\right.} \mathrm{Pd}-\mathrm{Cu}^{\left[{ }^{[1,82]}\right.} \mathrm{Pd}-\mathrm{Ga}^{[83]} \mathrm{Pd}-$ $\mathrm{Sn}_{1}{ }^{[84]}$ and $\mathrm{Pd}-\mathrm{Zn} .{ }^{[85,86]}$ Among the promoters, $\mathrm{Bi}$ and $\mathrm{Sn}$ behave similarly to $\mathrm{Pb}$ in the Lindlar catalyst because of their efficiency in reducing the binding energy of the double and triple bonds and suppressing hydride formation. ${ }^{[74]}$ For this reason, in both gas and liquid-phase, catalysts based on $\mathrm{Bi}$ and $\mathrm{Sn}$ showed a high degree of alkene selectivity (>95\%) and low oligomer and alkane formation, even at low modifier content (weight modifier/Pd ratio $<1$ ) (Figure 7 a). However, the distribution of the secondary metal is not as homogeneous as in $\mathrm{Pd}-\mathrm{Pb} .^{[74]}$ The use of $\mathrm{Ag}, \mathrm{Au}, \mathrm{Cu}$, and $\mathrm{Ga}$ as modifiers, on the other hand, 
generally alters the electronic properties of palladium, reducing the binding energies of both alkynes and alkenes. In general, the secondary metals are less prone to adsorb the reactants and/or block diffusion paths that potentially lead to oligomerization. ${ }^{[74]}$ Moreover, the dynamic response of secondary metals to form hydride and carbide is very poor as the high pressures can bury the secondary metal on the surface. ${ }^{[7]}$ Thus, a high loading of $\mathrm{Ag}, \mathrm{Au}, \mathrm{Cu}$, and $\mathrm{Ga}$ is preferred (weight modifier/Pd ratio $>1$ ), in order to obtain a better isolation of the active palladium sites. In some cases, intermetallic Pd-based compounds have been also studied with the aim of improving the activity and/or selectivity of the individual active phases.

For nitroarene hydrogenation, the catalysts developed were based on $\mathrm{Pt}-\mathrm{Cr}_{1}{ }^{[87,88]} \mathrm{Pt}-\mathrm{Mn}_{1}{ }^{[88]} \mathrm{Pt}-\mathrm{Fe}_{1}{ }^{[88]} \mathrm{Pt}-\mathrm{Co}_{1}{ }^{[88]} \mathrm{Pt}-\mathrm{Ni}^{\left[{ }^{[89]}\right.} \mathrm{Pt}-$

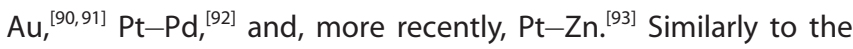
industrially-relevant $\mathrm{Pt}-\mathrm{Pb}$ and $\mathrm{Pt}-\mathrm{V}$ catalysts, the function of the secondary metal is to increase the rate of hydroxylamine hydrogenation through electronic contributions played on $\mathrm{Pt}$ by the secondary metal. The weight modifier/Pt ratio is generally $<1$. Recently, Kiwi-Minsker, Cardenas-Lizana, et al. have also reported $100 \%$ selectivity in the hydrogenation of chloronitroanilines over Pd-Au and Pd-Zn catalysts (Figure 7e). ${ }^{[94,95]}$

Sintering by metal agglomeration and Ostwald ripening as well as metal leaching are the main causes of catalyst deactivation in hydrogenation catalysis. In this respect, researchers are currently investigated new approaches to immobilize the metallic phase. Silica-based core-shell nanomaterials have emerged as promising materials because of their high thermal and leaching resistance and high tolerance to acidic conditions. ${ }^{[96,97]}$ Several synthetic methods to prepare silica shell nanomaterials with core metals and metal alloys have been reported. ${ }^{[98]}$ In some cases, magnetic nanoparticles (e.g., Co) are chosen for the core and palladium- or platinum-based alloys are employed on the surface. ${ }^{[98-101]}$ Hydrogenation tests over these materials have shown high activity, selectivity, and stability, although diffusion limitations might be present, particularly when bulky reactive substrates are selected. ${ }^{[96]}$

\subsection{Ensemble Control in Hybrid Materials}

Hybrid nanomaterials for selective hydrogenations are typically prepared through wet chemical routes or electrochemical dissolution of a sacrificial bulk anode. ${ }^{[103]}$ In the first case, an organically soluble reducing agent (e.g., hydrazine, borohydride, or superhydrides such as $\left.\operatorname{LiB}\left(\mathrm{C}_{2} \mathrm{H}_{4}\right)_{3} \mathrm{H}\right)$ is mixed with a metal precursor in the presence of a stabilizing agent. Upon stirring, colloidal metal nanoparticles are formed, which can be deposited on a carrier. Alternatively, the anode of an electrolytic cell can be dissolved in the presence of water and electric current. The migration of the metal to the cathode creates metal nanoparticles that are stabilized by the ligand in solution. Independently of the strategy utilized, the stabilizer (e.g., surfactant, polymer, dendrimer, etc.) controls the growth of the nanoclusters, preventing the colloidal nanoparticles from agglomeration and subsequent catalyst deactivation. The use of ionic liquids as modifier has been also demonstrated in recent years, with benefits particularly when electron-transfer properties derived from the $\mathrm{N}$-donor complexes are requested. ${ }^{[104]}$ However, owing to the high cost and potential toxicity of the ionic liquids, ${ }^{[105]}$ catalytic applications are still limited. In general, the combination of organic and inorganic moieties in hybrid catalysts complicates the materials characterization; thus, as highlighted in Figure 9, complementary techniques are necessary

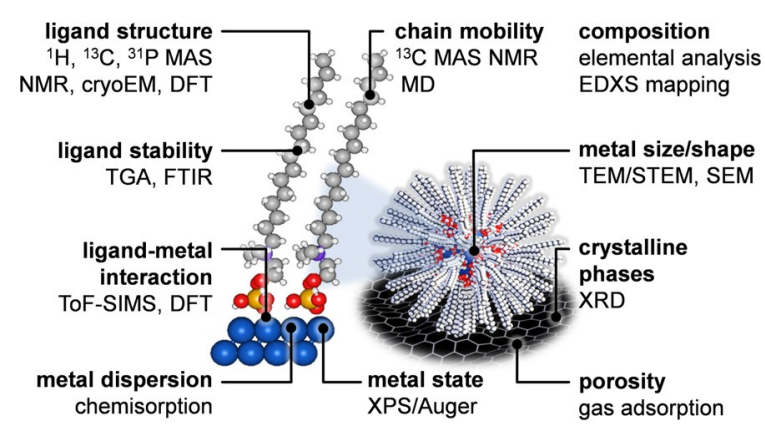

Figure 9. Overview of the complementary characterization methods required to assess structure and composition of the metal, ligand, and metal-ligand interphase of a ligand-modified catalyst.

to assess the structure and composition of the metal, ligand, and metal-ligand interphase. Table 1 collects some of the most exciting contributions in the field. In general, high activity and product selectivity $(>95 \%)$ can be obtained in very mild conditions, independently of the stabilizer applied. A number of studies, in particular, have shown that the performance of these catalysts is highly sensitive to the nature of the organic modifiers; ${ }^{[117]}$ thus, there has been a growing interest in developing ordered structures that can provide a systematic approach for having materials with well-defined structure for mechanistic investigations. In this context, self-assembled monolayers (i.e., organic compounds containing a sulfur headgroup that strongly interacts with the metal) have been used to modify the metal phase. ${ }^{[117]}$ Pioneering works of Marshall, Schwartz, and Medlin have demonstrated that the modification of metals by self-assembled monolayers can dramatically improve the product selectivity in hydrogenation. ${ }^{[117-119]}$ The enhanced selectivity was found to be independent of the tail functionality and attributed to electronic effects induced by the presence of the sulfur head-group, steric contributions, created by the presence of capping layers on the surface, active-site selection, owing to the preferential poisoning of unselective metallic sites, and molecular recognition, owing to the exploitation of intermolecular interactions between the reactants and modifiers to orient the reactants in a desirable way. ${ }^{[117-119]}$

Despite the great versatility of these synthetic approaches, the industrial scale up of these nanomaterials has been long hampered by several disadvantages, including the need for low-boiling point organic solvents and the addition of expensive or toxic reductants. The identification of hexadecyl-2-hydroxyethyl-dimethyl ammonium dihydrogen phosphate (HHDMA) as a ligand that combines both reducing and stabilizing functions in a single, water-soluble molecule, has enabled the first synthesis at industrial scale of colloidally prepared Pd, 


\begin{tabular}{|c|c|c|c|c|c|c|c|}
\hline Catalyst & Modifier & Reactant & $T[\mathrm{~K}]$ & $P[$ bar $]$ & $X[\%]$ & $S[\%]$ & ref. \\
\hline $\mathrm{Pd}$ & sodium 2-ethylhexylsulfosuccinate & 1-hexyne & $298-303$ & $1-10.5$ & $85-100$ & 99 & [90] \\
\hline $\mathrm{Pd}$ & poly(vinylpyrrolidone) & 1-hexyne & 298-303 & $1-10.5$ & $85-100$ & 99 & [106] \\
\hline Pt & cetyltrimethylammonium bromide & 1-hexyne & 298 & 1 & $33-78$ & 99 & [107] \\
\hline Pt & poly(vinylpyrrolidone) & 2-hexyne & $333-393$ & 1 & $7-90$ & 99 & [108] \\
\hline $\mathrm{Pd}$ & poly(vinylpyrrolidone) & 3-hexyn-1-ol & $283-298$ & $1-2.8$ & $40-100$ & 100 & [106] \\
\hline $\mathrm{Pd}$ & ionic liquids & 3-hexyn-1-ol & $283-298$ & $1-2.8$ & $40-100$ & 100 & [109] \\
\hline $\mathrm{Pd}$ & poly(ethylene oxide)-block-poly-2-vinylpyridine & 2-butyne-1,4-diol & $303-323$ & $1-6$ & 80 & 59 & [110] \\
\hline $\mathrm{Pd}$ & poly(vinylpyrrolidone) & 2-butyne-1,4-diol & 323 & 2.4 & 100 & 100 & [111] \\
\hline $\mathrm{Pd}$ & cetyltrimethylammonium bromide & 4-octyne & $283-303$ & $1-8$ & $4-100$ & 100 & [112] \\
\hline $\mathrm{Pd}$ & sodium dodecyl sulfate & 4-octyne & $283-303$ & $1-8$ & $4-100$ & 100 & [113] \\
\hline $\mathrm{Pd}$ & poly(vinylpyrrolidone) & 2-methyl-3-butyn-2-ol & $308-348$ & $2-10$ & $10-99$ & 99 & [40] \\
\hline $\mathrm{Pd}$ & sodium 2-ethylhexylsulfosuccinate & 2-methyl-3-butyn-2-ol & $308-348$ & $2-10$ & $10-99$ & 99 & [114] \\
\hline Pt & hyper cross linked polysterene & p-chloronitrobenzene & $303-348$ & $1-20$ & 95 & 100 & [115] \\
\hline Pt-Ru & poly(vinylpyrrolidone) & o-chloronitrobenzene & 298 & 10 & 100 & 100 & [116] \\
\hline $\mathrm{Pt}$ & hexadecyl-2-hydroxyethyl-dimethyl dihydrogenphospahte & nitrobenzene & $303-343$ & $1-20$ & $10-100$ & 100 & [116] \\
\hline
\end{tabular}

$\mathrm{Pt}$, and mixed Pd-Pt nanoparticles supported on titanium silicate and activated carbon. ${ }^{[120-123]}$ Vilé et al. ${ }^{[124,125]}$ have shown the versatility of this new generation of catalysts for the semihydrogenation of functionalized alkynes and nitroaromatics, with full selectivity (ca. $100 \%$ ) at high reaction rates $\left(10^{3} \mathrm{~mol}_{\text {product }} \mathrm{mol}_{\mathrm{Pd}}{ }^{-1} \mathrm{~h}^{-1}\right)$ (Figure 10). Notably, the reactions were conducted in flow chemistry mode, in view of the obvious benefits in terms of quality, safety, and energy saving. ${ }^{[124]}$ The outstanding performance exceeds the activity and selectivity of state-of-the-art commercial catalysts for selective hydrogenations. Complementary theoretical calculations and detailed characterization studies have shown that the ligand not only isolate and tailor the accessibility and the adsorption modes of reactants of the active site (geometric effects) but also tune the energy landscape felt by reactants and products close to the active site (electronic effects) (Figure 10a and b). ${ }^{[124-126]}$ In some cases, the ligand may also participate in the reaction, absorbing some of the $\mathrm{H}$ species after hydrogen activation (co-catalytic effects), ${ }^{[127]}$ and preventing the surface from forming hydride structures. A recent work from our groups has also demonstrated that the concentration-induced ligand ordering on the metal nanoparticles determines the catalytic response of hybrid palladium nanoparticles in hydrogenation. ${ }^{[139]}$ In fact, at low ligand content, the chains are almost flattened on the surface and the catalyst has a 2D-type surface, with only small pockets where non-poisoned $\mathrm{Pd}$ atoms can catalyze the reaction. At high ligand density, the aliphatic chains assume a more extended configuration, giving rise to a 3D-like material with larger ensemble for catalysis. These counterintuitive results are also related to the interplay of geometric and electronic effects and were never demonstrated before as the experimental and theoretical challenges reached are important. Still, many hurdles in the controlled synthesis of hybrid catalysts with variable ligand content and same metal concentration and average particle size, in the characterization of the ligand organization exist, and in the rationalization of its catalytic impact remain in the cradle. Extending this technology to
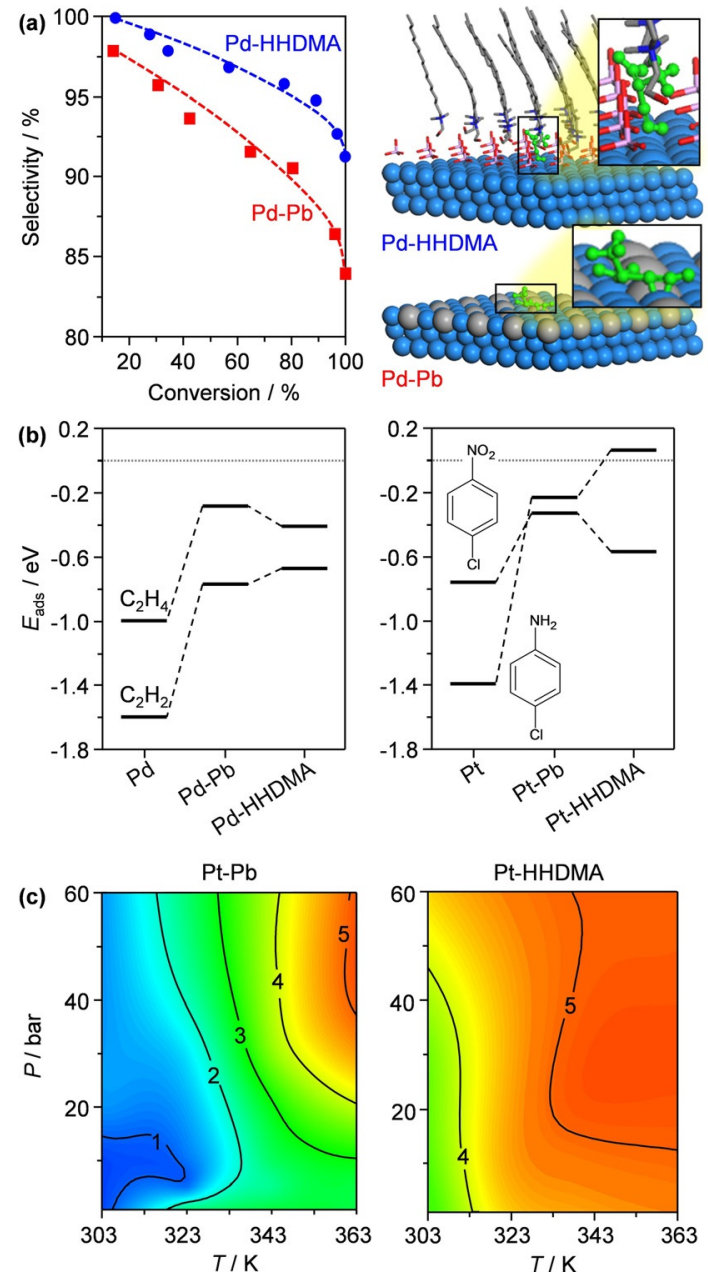

Figure 10. (a) Hydrogenation (left) and adsorption configuration (right) of 2methyl-3-butyn-2-ene over Pd-HHDMA and Pd-Pb. (b) Adsorption energy of acetylene, ethylene, chloronitrobenzene and chloronitroaniline over different Pd and Pt model surfaces. (c) Hydrogenation of 4-chloronitrobenzene over $\mathrm{Pt}-\mathrm{HHDMA}$ and Pt-Pb. The figures are adapted from ref. [124] and [125]. 
other hydrogenation metals (e.g., $\mathrm{Ag}, \mathrm{Au}, \mathrm{Ir}, \mathrm{Ni}, \mathrm{Rh}$, and $\mathrm{Ru}$ ) and discovering alternative ligands with similar properties to HHDMA are important outlooks in the field.

\subsection{Single-Atom Catalysts}

To maximize the product selectivity in hydrogenations, strategies to improve the isolation of the active phases have been often adopted. ${ }^{[124]}$ The ultimate frontier in this attempt is the single-atom catalyst, which contains isolates metals atomically embedded in a high-surface-area carrier. ${ }^{[128,129]}$ This type of materials combines the benefits of heterogeneous and homogeneous catalysis, with none of the drawbacks existing from organometallic design. The structure and properties of the carrier are important to entrap the catalytically active phase in an isolated form. Single-site catalysts have sporadically appeared in hydrogenation research and only few success stories can be mentioned. In fact, their preparation is challenging because the thermodynamic tendency of isolated metals to leach and/ or agglomerate. ${ }^{[130]}$ The pioneering work of Flytzani-Stephanopoulos and co-workers demonstrated that a single $\mathrm{Cu}(111)$ crystal doped with atomically-dispersed Pd species can activate hydrogen and display activity in the hydrogenation of acetylene and styrene under ultra-high vacuum conditions (Figure $11 \mathrm{a}) .{ }^{[131]}$ However, the palladium atoms on this copper surface are incorporated by heating a palladium source in a highvacuum chamber, using an electron beam. This method is suitable for preparing single-atom crystals but does not readily translate to the production of industrial-scale quantities of catalysts. ${ }^{[131]}$ Besides, the relatively low ethylene selectivity (30\%) at moderate reactant conversions (10-20\%) limits the applica- bility of the work. Zhang and co-workers recently prepared a single-site platinum catalyst anchoring $\mathrm{Pt}$ species on $\mathrm{FeO}_{x}$ support (Figure $11 \mathrm{~b}) .^{[132,133]}$ Applied in the hydrogenation of functionalized nitroarenes, the materials demonstrated high activity $\left(T O F=\right.$ ca. $\left.10^{4} \mathrm{~h}^{-1}\right)$ and chemoselectivity to the desired product (ca. $100 \%$ ), which was attributed to the presence of positively charged platinum atoms in the system (Figure $11 \mathrm{c}$ ). The catalyst, however, showed deactivation within the first four cycles of reaction.

A stable single-site catalyst has been recently prepared by embedding atomic palladium into mesoporous polymeric graphitic carbon nitride $\left(\mathrm{mpg}-\mathrm{C}_{3} \mathrm{~N}_{4}\right){ }^{[134]}$ a material with hierarchical level of porosity and intriguing electronic properties (Figure $11 \mathrm{~d}$ ). The authors demonstrated that the isolated atoms were tenaciously attached to the nitrogen atoms of the cavities of $\mathrm{mpg}-\mathrm{C}_{3} \mathrm{~N}_{4}$. The absence of palladium-palladium bonds was confirmed by X-ray-absorption spectroscopy and aberration-corrected transmission electron microscopy. In alkyne and nitroarene hydrogenation, the material surpassed the activity of conventional heterogeneous catalysts based on nanoparticles, while maintaining an outstanding degree of product selectivity (>90\%) and leaching/agglomeration resistance for more than $20 \mathrm{~h}$. The performance was rationalized for the first time at a molecular level, employing DFT calculations, showing that the high activity and selectivity can be attributed to the facile hydrogen activation and reactant adsorption on the atomically dispersed Pd sites. ${ }^{[134]}$

Following this work, Lu et al. have reported that atomically dispersed Pd species can also be incorporated by atomic layer deposition, after introduction of anchoring sites on pristine graphene by high-temperature oxidation. ${ }^{[135]}$ This material was (a)

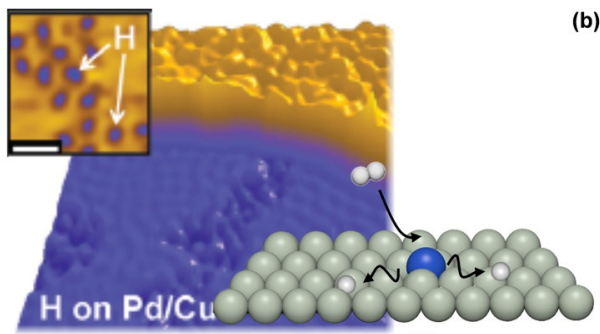

(b)

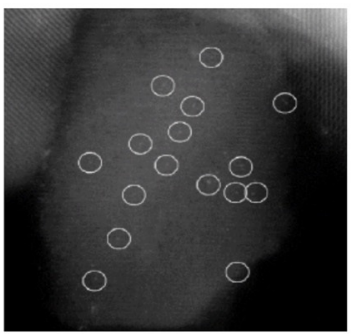

(d)

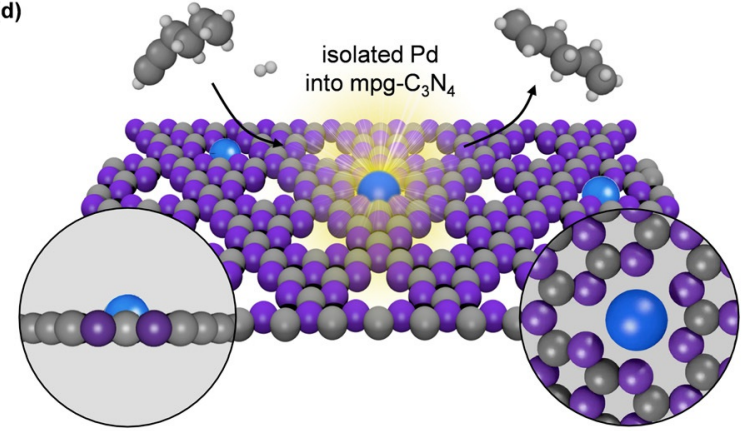

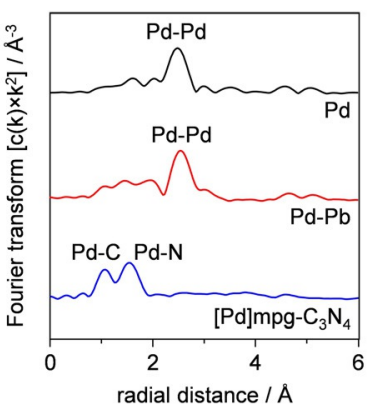

(c)
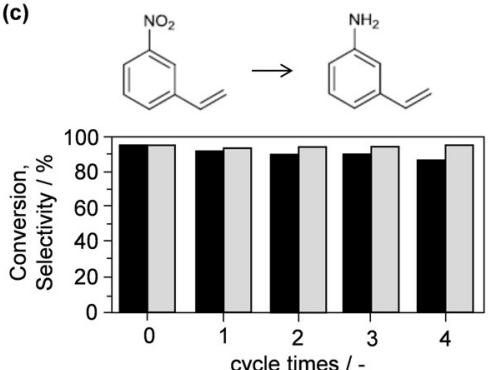

cycle times /

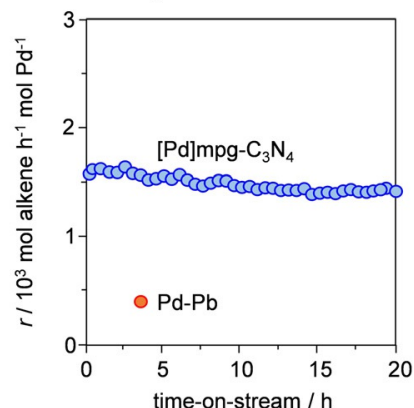

Figure 11. Uses of single-site heterogeneous catalysts in selective hydrogenations of alkynes and nitroarenes. (a) Atomic-force microscopy of Pd/Cu(111) demonstrated the possibility of hydrogen splitting over atomically-dispersed palladium atoms. (b) High-resolution transmission electron microscopy of $\mathrm{Pt} /$ FeO $\mathrm{O}_{x}$. The atomic platinum species anchored to the support are encircled. (c) Hydrogenation of nitrostyrene over $\mathrm{Pt}_{/} / \mathrm{FeO}_{\mathrm{x}}$ showing the stability and high product selectivity of the catalyst. (d) Structure of [Pd]mpg- $\mathrm{C}_{3} \mathrm{~N}_{4}$, extended X-ray absorption fine structure spectroscopy, and hydrogenation of 1-hexyne over [Pd]mpg$\mathrm{C}_{3} \mathrm{~N}_{4}$. The results for Pd-Pb and $\mathrm{Pd}$ are also plotted. The Figure is adapted from refs. [131] (a), [132] (b,c), and [134] (d). 
tested in the hydrogenation of butadiene, showing $100 \%$ product selectivity at $95 \%$ conversion at mild reaction conditions (300-350 K); in addition, excellent durability during $50 \mathrm{~h}$ of reaction time was achieved, demonstrating also in this case the benefits of atom immobilization in defined cavities in order to prepare single-site heterogeneous catalysts.

The incorporation of a metal in an appropriate porous carrier such as carbon nitrides is generally performed post-synthetically, by impregnation of minute amount of a metal salt, followed by metal reduction and/or drying. This synthetic methodology, however, could lead to an undesirable formation of clusters during synthesis. ${ }^{[136]}$ An alternative approach to better control the introduction of the metals into the carrier network potentially comprises the addition of a metal salt during the synthesis of the support. Such method can provide a more homogeneous metal distribution. In this direction, unpublished results from our groups have demonstrated that silver tricyanomethanide can be used as a reactive co-monomer during carbon nitride synthesis to introduce both negative charges and silver atoms to the system. The successful introduction of the extra electron density has been proven by electron microscopy evaluation, photoluminescence measurements, X-ray photoelectron spectroscopy investigations, and measurements of surface Zeta-potential. These results will be soon disclosed. Extrapolating this synthetic approach to prepare a wide range of single-site heterogeneous catalysts for hydrogenations (e.g., based on $\mathrm{Ag}, \mathrm{Au}, \mathrm{Ir}, \mathrm{Ni}, \mathrm{Rh}$, and $\mathrm{Ru}$ ) and identifying alternative carriers with similar properties to carbon nitrides remain few of the most urgent scopes. In the long term, it can be envisioned the development of 'structured reactors' containing isolated metal atoms in the washcoat, to permit almost total control over all relevant length scales for mass transfer and catalysis. $^{[137,138]}$

\section{Conclusions and Outlook}

Hydrogenation catalysis stands at the basis of our chemical industry. This mature field, for which core research was developed more than half a century ago, is now facing new challenges owing to environmental and health regulations. The field has reemerged with unusual strength and is benefiting from advances in materials synthesis, improved characterization techniques, new reactor developments, and the robustness of the most advanced theoretical simulations that can provide an integrated approach towards the molecular understanding of the catalytic phenomena. More importantly, in a field with little innovation over the past sixty years, three new generations of catalysts have been developed in the last ten years. Out of these new generations: alternative materials (like oxides), hybrid nanoparticles (with inorganic and organic counterparts), and single-atom catalysts demonstrate that there is a bright future ahead of us and many more materials are awaiting further explorations. This review contributes to this interest, summarizing the approaches developed over the past 10 years and showing how the traditional families of hydrogenation catalysts, for bulk and fine chemicals, can be understood using the same conceptual principles.
We expect that the next decade will foresee new, targeted applications in biomass research. Many biomass-related reactions are hydrogenations and, in most cases, high-loading Ru catalysts with undefined nanostructure are applied. The use of hybrid and single-site catalysts has not been demonstrated to date, but could be major breakthroughs in the next years. Applications in the pharmaceutical and fine chemical industries will also remain important scope of applications of hydrogenation catalysis, considering the large (and yearly increasing) number of high added-value compounds with biological functions. The dream of a green, sustainable, and intensified hydrogenation chemistry producing no byproducts and operating with minimal energetic impact has never been so close to reality.

Keywords: heterogeneous catalysis • hydrogenation nanostructured materials • selectivity control • single-site catalysis

[1] R. J. Farrauto, C. H. Bartholomew, Fundamentals of Industrial Catalytic Processes, Chapman\&Hall, New York, 1997, p. 411.

[2] H. F. Rase, Handbook of Commercial Catalysts: Heterogeneous Catalysts, CRC Press, Boca Raton, FL, 2000, p. 110.

[3] P. Pollak, Fine Chemicals: the Industry and the Business, Wiley, Hoboken, NJ, 2011, p. 3.

[4] P. N. Rylander, Hydrogenation Methods, Academic Press, New York, 1990, p. 13.

[5] S. Nishimura, Handbook of Heterogeneous Catalytic Hydrogenation for Organic Synthesis, Wiley, New York, 2001, p. 63.

[6] R. A. Sheldon, H. van Bekkum, Fine Chemicals through Heterogeneous Catalysis, Wiley-VCH, Weinheim, 2001, p. 351.

[7] P. Sabatier, J.-B. Senderens, Compt. Rend. 1899, 128, 1173.

[8] F. Haber, Z. Elektrochem. Angew. Phys. Chem. 1898, 4, 410.

[9] J. Horiuti, M. Polanyi, Trans. Faraday Soc. 1934, 30, 1164.

[10] H. Lindlar, Patent AT168606, 1949.

[11] H. Lindlar, Helv. Chim. Acta 1952, 35, 446.

[12] H.-U. Blaser, H. Steiner, M. Studer, ChemCatChem 2009, 1, 210.

[13] Directive 2002/95/EC, 2002.

[14] M. L. Derrien, Stud. Surf. Sci. Catal. 1986, 27, 613.

[15] A. Borodzinski, G. C. Bond, Catal. Rev. Sci. Eng. 2006, 48, 91.

[16] G. C. Bond, Metal-catalysed Reactions of Hydrocarbons, Springer, New York, 2005, p. 292.

[17] A. Molnár, A. Sárkány, M. Varga, J. Mol. Catal. A 2001, 173, 185.

[18] H.-U. Blaser, C. Malan, B. Pugin, F. Spindler, H. Steiner, M. Studer, Adv. Synth. Catal. 2003, 345, 103.

[19] Y. Segura, N. López, J. Pérez-Ramírez, J. Catal. 2007, 247, 383.

[20] B. Bridier, N. López, J. Pérez-Ramírez, Dalton Trans. 2010, 39, 8412.

[21] D. Teschner, J. Borsodi, A. Wootsch, Z. Révay, M. Hävecker, A. KnopGericke, S. D. Jackson, R. Schlögl, Science 2008, 320, 86.

[22] A. Borodzinski, G. C. Bond, Catal. Rev. Sci. Eng. 2008, 50, 379.

[23] M. García-Mota, B. Bridier, J. Pérez-Ramírez, N. López, J. Catal. 2010, 273, 92.

[24] M. García-Mota, J. Gómez-Díaz, G. Novell-Leruth, C. Vargas-Fuentes, L. Bellarosa, B. Bridier, J. Pérez-Ramírez, N. López, Theor. Chem. Acc. 2011, $128,663$.

[25] U. Siegrist, P. Baumeister, H. U. Blaser, M. Studer, Catalysis of Organic Reactions, Dekker, New York, 1998, p. 207.

[26] U. Siegrist, P. Baumeister, Patent WO9532941, 1995.

[27] P. Anastas, N. Eghbali, Chem. Soc. Rev. 2010, 39, 301.

[28] B. M. Trost, Science 1991, 254, 1471.

[29] R. A. Sheldon, Green Chem. 2007, 9, 1273.

[30] G. Vilé, J. Pérez-Ramírez, Nanoscale 2014, 6, 13476.

[31] G. Vilé, D. Baudouin, I. N. Remediakis, C. Copéret, N. López, J. PérezRamírez, ChemCatChem 2013, 5, 3750.

[32] E. Oakton, G. Vilé, D. Levine, E. Zocher, D. Baudouin, J. Pérez-Ramírez, C. Copéret, Dalton Trans. 2014, 43, 15138. 
[33] B. Bridier, N. López, J. Pérez-Ramírez, J. Catal. 2010, 269, 80.

[34] S. Abelló, D. Verboekend, B. Bridier, J. Pérez-Ramírez, J. Catal. 2008 , 259, 85.

[35] C. Rangheard, C. de Julián Fernández, P.-H. Phua, J. Hoorn, L. Lefort, J. G. de Vries, Dalton Trans. 2010, 39, 8464

[36] S. A. Nikolaev, V. V. Smirnov, Catal. Today 2009, 147, S336.

[37] N. Semagina, A. Renken, L. Kiwi-Minsker, J. Phys. Chem. C 2007, 111, 13933.

[38] M. Ruta, N. Semagina, L. Kiwi-Minsker, J. Phys. Chem. C 2008, 112, 13635.

[39] I. Yuranov, P. Moeckli, E. Suvorova, P. Buffat, L. Kiwi-Minsker, A. Renken, J. Mol. Catal. A 2003, 192, 239.

[40] M. Crespo-Quesada, A. Yarulin, M. Jin, Y. Xia, L. Kiwi-Minsker, J. Am. Chem. Soc. 2011, 133, 12787.

[41] A. Corma, P. Serna, P. Conception, J. J. Calvino, J. Am. Chem. Soc. 2008, 130,8748

[42] C. Liu, Z. Zhou, Z. Wu, M. Fransson, B. Zhou, Synlett 2009, 4, 595.

[43] F. Studt, F. Abild-Pedersen, T. Bligaard, R. Z. Sørensen, C. H. Christensen, J. K. Nørskov, Science 2008, 320, 1320.

[44] B. Bridier, J. Pérez-Ramírez, J. Am. Chem. Soc. 2010, 132, 4321.

[45] B. Bridier, J. Pérez-Ramírez, A. Knop-Gericke, R. Schlögl, D. Teschner, Chem. Sci. 2011, 2, 1379

[46] M. Armbrüster, K. Kovnir, M. Friedrich, D. Teschner, G. Wowsnick, M. Hahne, P. Gille, L. Szentmiklósi, M. Feuerbacher, M. Heggen, F. Girgsdies, D. Rosenthal, R. Schlögl, Y. Grin, Nat. Mater. 2012, 11, 690.

[47] A. Corma, P. Serna, Science 2006, 313, 332.

[48] M. Mavrikakis, P. Stoltze, J. K. Norskov, Catal. Lett. 2000, 64, 101.

[49] V. I. Komarewsky, L. B. Bos, J. R. Coley, J. Am. Chem. Soc. 1948, 70, 428

[50] E. J. Grootendorst, R. Pestman, R. M. Koster, V. Ponec, J. Catal. 1994 148, 261.

[51] Y. Sakata, V. Ponec, Appl. Catal. 1998, 166, 173.

[52] G. Vilé, B. Bridier, J. Wichert, J. Pérez-Ramírez, Angew. Chem. Int. Ed. 2012, 51, 8620; Angew. Chem. 2012, 124, 8748.

[53] G. Vilé, S. Wrabetz, L. Floryan, M. E. Schuster, F. Girgsdies, D. Teschner, J. Pérez-Ramírez, ChemCatChem 2014, 6, 1928.

[54] G. Vilé, S. Colussi, F. Krumeich, A. Trovarelli, J. Pérez-Ramírez, Angew. Chem. Int. Ed. 2014, 53, 12069; Angew. Chem. 2014, 126, 12265.

[55] J. Carrasco, G. Vilé, D. Fernández-Torre, R. Pérez, J. Pérez-Ramírez, M. V. Ganduglia-Pirovano, J. Phys. Chem. C 2014, 118, 5352.

[56] M. García-Melchor, N. López, J. Phys. Chem. C 2014, 118, 10921

[57] M. García-Melchor, L. Bellarosa, N. López, ACS Catal. 2014, 4, 4015.

[58] D. R. Mullins, Surf. Sci. Rep. 2015, 70, 42

[59] D. Fernández-Torre, J. Carrasco, M. V. Ganduglia-Pirovano, R. Pérez, J. Chem. Phys. 2014, 141, 014703.

[60] F. R. Negreiros, M. Farnesi Camellone, S. Fabris, J. Phys. Chem. C 2015 119, 21567.

[61] G. Vilé, P. Dähler, J. Vecchietti, M. Baltanás, S. Collins, M. Calatayud, A. Bonivardi, J. Pérez-Ramírez, J. Catal. 2015, 324, 69.

[62] S. M. Schimming, G. S. Foo, O. D. LaMont, A. K. Rogers, M. M. Yung, A. D. D'Amico, C. Sievers, J. Catal. 2015, 329, 335.

[63] K. V. Kovtunov, D. A. Barskiy, O. G. Salnikov, A. K. Khudorozhkov, V. I. Bukhtiyarov, I. P. Prosvirin, I. V. Koptyug, Chem. Commun. 2014, 50, 875.

[64] E. W. Zhao, H. Zheng, R. Zhou, H. E. Hagelin-Weaver, C. R. Bowers, Angew. Chem. Int. Ed. 2015, 54, 14270; Angew. Chem. 2015, 127 14478.

[65] H.-Z. Zhu, Y.-M. Lu, J. Fan, S.-H. Yu, Nanoscale 2013, 5, 7219.

[66] J. Song, Z.-F. Huang, L. Pan, J. Zou, X. Zhang, L. Wang, ACS Catal. 2015 5,6594 .

[67] S. Chrétien, H. Metiu, J. Phys. Chem. C 2015, 119, 19876.

[68] A. Primo, F. Neatu, M. Florea, V. Parvulescu, H. Garcia, Nat. Commun. 2014, 5, 5291.

[69] W. Bonrath, M. Eggersdorfer, T. Netscher, Catal. Today 2007, 121, 45

[70] W. Bonrath, J. Medlock, J. Schütz, B. Wüstenberg, T. Netscher, Hydrogenation, InTech, Balterswil, 2012, p. 69.

[71] S. Vernuccio, P. R. von Rohr, J. Medlock, Ind. Eng. Chem. Res. 2015, 54, 11543.

[72] M. Sankar, N. Dimitratos, P. J. Miedziak, P. P. Wells, C. J. Kielye, G. J. Hutchings, Chem. Soc. Rev. 2012, 41, 8099.

[73] S. Zafeiratos, S. Piccinin, D. Teschner, Catal. Sci. Technol. 2012, 2, 1787

[74] N. López, C. Vargas-Fuentes, Chem. Commun. 2012, 48, 1379.

[75] A. Pachulski, R. Schodel, P. Claus, Appl. Catal. A 2011, 400, 14.
[76] D. Mei, M. Neurock, C. M. Smith, J. Catal. 2009, 268, 181.

[77] P. Han, S. Axnanda, I. Lyubinetsky, D. W. Goodman, J. Am. Chem. Soc 2007, 129, 14355.

[78] C. Keresszegi, J. D. Grunwaldt, T. Mallat, A. Baiker, Chem. Commun 2003, 2304.

[79] J. Sá, J. Montero, E. Duncan, J. A. Anderson, Appl. Catal. B 2007, 73, 98.

[80] J. A. Anderson, J. Mellor, R. P. Wells, J. Catal. 2009, 261, 208.

[81] S. Sitthisa, T. Pham, T. Prasomsri, T. Sooknoi, R. G. Mallinson, D. E. Resacco, J. Catal. 2011, 41, 8099.

[82] A. E. Baber, H. L. Tierney, T. J. Lawton, E. C. H. Sykes, ChemCatChem 2011, 3, 607.

[83] M. Armbrüster, K. Kovnir, M. Behrens, D. Teschner, Y. Grin, R. Schlögl, Am. Chem. Soc. 2010, 132, 14745.

[84] G. Hamm, T. Schmidt, J. Breitbach, D. Franke, C. Becker, K. Wandelt, Z Phys. Chem. 2009, 223, 209.

[85] N. Semagina, L. Kiwi-Minsker, Catal. Lett. 2009, 127, 334

[86] M. W. Tew, H. Emerich, J. A. van Bokhoven, J. Phys. Chem. C 2011, 115, 8457.

[87] X. Han, R. Zhou, G. Lai, X. Zheng, Catal. Today 2004, 93-95, 433.

[88] X. Han, Q. Chen, R. X. Zhou, J. Mol. Catal. A 2007, 277, 210.

[89] Y. Wu, S. Cai, D. Wang, W. He, Y. Li, J. Am. Chem. Soc. 2012, 134, 8975

[90] K.-Q. Sun, Y.-C. Hong, G.-R. Zhang, B.-Q. Xu, ACS Catal. 2011, 1, 1336.

[91] J. Zhang, G. Chen, D. Guay, M. Chaker, D. Ma, Nanoscale 2014, 6, 2125.

[92] X. Huang, Y. Li, Y. Li, H. Zhou, X. Duan, Y. Huang, Nano Lett. 2012, 12, 4265 .

[93] C. Berguerand, A. Yarulin, F. Cárdenas-Lizana, J. Wärnå, E. Sulman, D. Yu. Murzin, L. Kiwi-Minsker, Ind. Eng. Chem. Res. 2015, 54, 8659.

[94] F. Cárdenas-Lizana, S. Gomez-Quero, A. Hugon, L. Delannoy, C. Louis, M. Keane, J. Catal. 2009, 262, 235.

[95] F. Cárdenas-Lizana, Y. Hao, M. Crespo-Quesada, I. Yuranov, X. Wang, M. A. Keane, L. Kiwi-Minsker, ACS Catal. 2013, 3, 1386

[96] Y. Wang, J. Liu, P. Wang, C. J. Werth, T. J. Strathmann, ACS Catal. 2014, 4, 3551.

[97] A. M. Henning, J. Watt, P. J. Miedziak, S. Cheong, M. Santonastaso, M. Song, Y. Takeda, A. I. Kirkland, S. H. Taylor, R. D. Tilley, Angew. Chem. Int Ed. 2013, 52, 1477-1480; Angew. Chem. 2013, 125, 1517-1520.

[98] V. Kelsen, B. Wendt, S. Werkmeister, K. Junge, M. Beller, B. Chaudret, Chem. Commun. 2013, 49, 3416.

[99] R. V. Jagadeesh, A.-E. Surkus, H. Junge, M.-M. Pohl, J. Radnik, J. Rabeah, H. Huan, V. Schünemann, A. Brückner, M. Beller, Science 2013, 342, 1073.

[100] Q. M. Kainz, R. Linhardt, R. Grass, G. Vilé, J. Pérez-Ramírez, W. J. Stark O. Reiser, Adv. Funct. Mater. 2014, 24, 2020.

[101] R. Linhardt, Q. M. Kainz, R. N. Grass, W. J. Stark, O. Reiser, RSC Adv. 2014, 4, 8541.

[102] H. C. Zeng, Acc. Chem. Res. 2013, 46, 226.

[103] C. Jia, F. Schüth, Phys. Chem. Chem. Phys. 2011, 13, 2457.

[104] R. Venkatesan, M. H. G. Prechtl, J. D. Scholten, R. P. Pezzi, G. Machadoc, J. Dupont, J. Mater. Chem. 2011, 21, 3030.

[105] T. P. Thuy Pham, C. W. Cho, Y. S. Yun, Water Res. 2010, 44, 352.

[106] C. Evangelisti, N. Panziera, A. D'Alessio, L. Bertinetti, M. Botavina, G, Vitulli, J. Catal. 2010, 272, 246.

[107] A. Mastalir, B. Rac, Z. Kiraly, G. Tasi, A. Molnar, Catal. Commun. 2008, 9, 762

[108] C. Lange, D. De Caro, A. Gamez, S. Storck, J. S. Bradley, W. F. Maier, Langmuir 1999, 15, 5333

[109] T. N. Gieshoff, A. Welther, M. T. Kessler, M. H. G. Prechtl, A. J. von Wangelin, Chem. Commun. 2014, 50, 2261.

[110] N. Semagina, E. Joannet, S. Parra, E. Sulman, A. Renken, L. Kiwi-Minsker Appl. Catal. A 2005, 280, 141

[111] M. M. Telkar, C. V. Rode, R. V. Chaudhari, S. S. Joshi, A. M. Nalawade, Appl. Catal. A 2004, 273, 11

[112] A. Mastalir, Z. Kiraly, F. Berger, Appl. Catal. A 2004, 269, 161.

[113] A. Mastalir, Z. Kiraly, J. Catal. 2003, 220, 372.

[114] N. Semagina, A. Renken, D. Laub, L. Kiwi-Minsker, J. Catal. 2007, 246, 308.

[115] F. Cárdenas-Lizana, C. Berguerand, I. Yurinov, L. Kiwi-Minsker, J. Catal. 2013, 301, 103

[116] M. Liu, J. Zhang, J. Liu, W. W. Yu, J. Catal. 2011, 278, 1.

[117] S. T. Marshall, M. O'Brien, B. Oetter, A. Corpuz, R. M. Richards, D. K Schwartz, J. W. Medlin, Nat. Mater. 2010, 9, 853. 
[118] S. H. Pang, C. A. Schoenbaum, D. K. Schwartz, J.W. Medlin, Nat Commun. 2013, 4, 92.

[119] C. A. Schoenbaum, D. K. Schwartz, J. W. Medlin, Acc. Chem. Res. 2014 47, 1438.

[120] P. T. Witte, P. H. Berben, S. Boland, E. H. Boymans, D. Vogt, J. W. Geus, J. G. Donkervoort, Top. Catal. 2012, 55, 505.

[121] E. Boymans, S. Boland, P. T. Witte, C. Müller, D. Vogt, ChemCatChem 2013, 5, 431.

[122] P. T. Witte, S. Boland, F. Kirby, R. van Maanen, B. F. Bleeker, D. A. M de Winter, J. A. Post, J. W. Geus, P. H. Berben, ChemCatChem 2013, 5 , 582.

[123] E. H. Boymans, P. T. Witte, D. Vogt, Catal. Sci. Technol. 2015, 5, 176.

[124] G. Vilé, N. Almora-Barrios, S. Mitchell, N. López, J. Pérez-Ramírez, Chem. Eur. J. 2014, 20, 5926.

[125] G. Vilé, N. Almora-Barrios, N. López, J. Pérez-Ramírez, ACS Catal. 2015, 5, 3767.

[126] S. W. T. Price, K. Ignatyev, K. Geraki, M. Basham, J. Filik, N. T. Vo, P. T. Witte, A. M. Beale, J. F. W. Mosselmans, Phys. Chem. Chem. Phys. 2015, $17,521$.

[127] I. Cano, A. M. Chapman, A. Urakawa, P. W. M. N. van Leuween, J. Am. Chem. Soc. 2014, 136, 2520.

[128] J. M. Thomas, R. Raya, D. W. Lewis, Angew. Chem. Int. Ed. 2005, 44 6456; Angew. Chem. 2005, 117, 6614

[129] J. M. Thomas, Design and Applications of Single-Site Heterogeneous Catalysis, Imperial College Press, London, 2012, p. 3.
[130] X. Yang, A. Wang, B. Qiao, J. Li, J. Liu, T. Zhang, Acc. Chem. Res. 2013, $46,1740$.

[131] G. Kyriakou, M. B. Boucher, A. D. Jewell, E. A. Lewis, T. J. Lawton, A. E. Baber, H. L. Tierney, M. Flytzani-Stephanopolous, E. C. H. Sykes, Science 2012, 335, 1209.

[132] H. Wei, X. Liu, A. Wang, L. Zhang, B. Qiao, X. Yang, Y. Huang, J. Miao, T. Zhang, Nat. Commun. 2014, 5, 5634.

[133] J. Lin, B. Qiao, N. Li, L. Li, X. Sun, J. Liu, X. Wang, T. Zhang, Chem Commun. 2015, 51, 7911.

[134] G. Vilé, D. Albani, M. Nachtegaal, Z. Chen, D. Dontsova, M. Antonietti, N. López, J. Pérez-Ramírez, Angew. Chem. Int. Ed. 2015, 54, 11265; Angew. Chem. 2015, 127, 11417.

[135] H. Yan, H. Cheng, H. Yi, Y. Lin, T. Yao, C. Wang, J. Li, S. Wei, J. Lu, J. Am. Chem. Soc. 2015, 137, 10484.

[136] J. M. Thomas, Nature 2015, 525, 325.

[137] M. T. Kreutzer, F. Kapteijn, J. A. Moulijn, Catal. Today 2006, 111, 111-118.

[138] J. M. Winterbottom, H. Marwan, E. H. Stitt, R. Natividad, Catal. Today 2003, 79, 391

[139] D. Albani, G. Vilé, S. Mitchell, P. T. Witte, N. Almora-Barrios, R. Verel, N. López, J. Pérez-Ramírez, Catal. Sci. Technol. 2016, DOI: 10.1039/ C5CY01921D. 